\title{
Visible-Light-Driven Rotation of Molecular Motors in a Dual- Function Metal-Organic Framework Enabled by Energy Transfer
}

\author{
Wojciech Danowski, Fabio Castiglioni, Andy S. Sardjan, Simon Krause, Lukas Pfeifer, Diederik Roke, \\ Angiolina Comotti, Wesley R. Browne, * and Ben L. Feringa*
}

Cite This: J. Am. Chem. Soc. 2020, 142, 9048-9056

Read Online

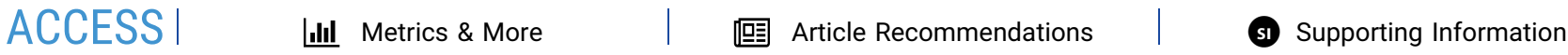

ABSTRACT: The visible-light-driven rotation of an overcrowded alkene-based molecular motor strut in a dual-function metalorganic framework (MOF) is reported. Two types of functional linkers, a palladium-porphyrin photosensitizer and a bispyridinederived molecular motor, were used to construct the framework capable of harvesting low-energy green light to power the rotary motion. The molecular motor was introduced in the framework using the postsynthetic solvent-assisted linker exchange (SALE) method, and the structure of the material was confirmed by powder (PXRD) and single-crystal X-ray (SC-XRD) diffraction. The large decrease in the phosphorescence lifetime and intensity of the porphyrin in the MOFs upon introduction of the molecular motor

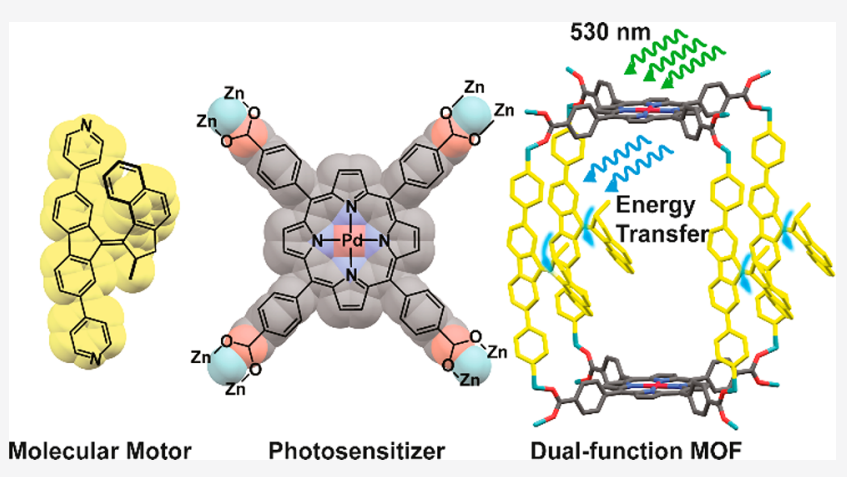
pillars confirms efficient triplet-to-triplet energy transfer between the porphyrin linkers and the molecular motor. Near-infrared Raman spectroscopy revealed that the visible light-driven rotation of the molecular motor proceeds in the solid state at rates similar to those observed in solution.

\section{INTRODUCTION}

Development of artificial molecular machines and motors allows for the design and construction of tailor-made molecular architectures capable of executing precisely controlled nanoscale structural motion. ${ }^{1-8}$ Among these artificial systems, overcrowded alkene-based molecular motors attract considerable attention due to their chirality controlled photochemically driven repetitive unidirectional rotary motion. ${ }^{9-11}$ Although it has been demonstrated that these molecules can perform various tasks in solution, such as control over the stereochemical outcome of catalytic reactions, ${ }^{12}$ Brownian motion precludes the cooperative action required to achieve functions beyond molecular dimensions. ${ }^{5,8,13,14}$ Achieving ensemble action with artificial molecular machines therefore requires that the randomizing effects of the thermal motion are eliminated by assembly on surfaces ${ }^{15-17}$ or integration into the larger systems. ${ }^{14}$ Incorporation and immobilization of these molecules in various supramolecular architectures, including organo- $^{18}$ and hydrogels, ${ }^{19,20}$ polymers, ${ }^{21,22}$ liquid crystals, ${ }^{23-26}$ or self-assembled monolayers, ${ }^{15-17}$ provided a way to amplify and harness their light-induced rotational motion to form responsive materials with tunable properties, including adaptive polymers, $^{21,22,27,28}$ artificial muscles, ${ }^{19,20}$ and responsive surfaces. ${ }^{29}$ For overcrowded alkene-based materials the use of UV light to drive the molecular motion limits such efforts due to limited penetration depth (due to the scattering) and potential damage by destructive photochemical pro- cesses. ${ }^{11,30,31}$ Therefore, development of reliable and practical visible-light excitation strategies that are compatible with a chosen material represents a major challenge crucial for further advancement of these dynamic systems.

The most common approaches to red shifting of the excitation wavelength of the overcrowded alkene-based molecular motors are based on HOMO-LUMO gap engineering featuring extension of the aromatic system, ${ }^{32}$ functionalization with donor-acceptor substituents, ${ }^{33,34}$ or formation of metal complexes. ${ }^{35}$ Although successful, these approaches may reduce the quantum yield of photoisomerization $^{32}$ and are so far limited in the absorption shift (only to the blue part of the visible spectrum; maximum of absorption ca. $450 \mathrm{~nm}) .{ }^{34}$ Furthermore, the resulting molecular architectures are synthetically more challenging to incorporate in a given material scaffold. ${ }^{32,35,36}$ An alternative approach to achieve visible-light-driven rotation of these molecules is to take advantage of intra- or intermolecular sensitization through triplet energy transfer from a second chromophore. ${ }^{37}$ This strategy not only reduces the synthetic efforts but also allows

Received: March 19, 2020

Published: April 23, 2020 
one to tune the excitation wavelength over a broad spectral range limited only by the choice of a photosensitizer and triplet-triplet energy transfer requirements. ${ }^{38}$ Furthermore, it has been successfully applied to operate several types of photoswitches by visible light including azobenzenes, ${ }^{39,40}$ stilbenes, ${ }^{41,42}$ and dithienylethenes. ${ }^{43,44}$

Metal-organic frameworks (MOFs) constitute a class of hybrid materials composed of inorganic nodes and organic linkers connected in a three-dimensional crystalline, highly porous network. ${ }^{45-47}$ Due to the high inherent porosity in these structures, sufficient internal free volume is present to allow for stimuli-responsive structural transformations ${ }^{48-57}$ or rotational $^{58-64}$ and translational ${ }^{65}$ motion of parts of the organic linkers organized in the crystalline solid. In addition, the structural diversity and chemical tunability of these materials makes them ideal platforms to achieve spatial coorganization of functional molecules ${ }^{66,67}$ and chromophores. ${ }^{68}$ Recent studies on light-harvesting multicomponent MOFs revealed that facile and long-distance energy migration can be achieved between light-absorbing nodes and/or linkers in MOFs of various architectures. ${ }^{69-72}$ Furthermore, the incorporation of photochromic dithienylethene struts in a layered porphyrin MOFs provided a method for photocontrol over energy transfer between adjacent chromophores and efficiency of singlet oxygen generation. ${ }^{73,74}$

Recently, we demonstrated that a molecular motor incorporated as a strut in a pillared-paddlewheel MOF is capable of performing unhindered, large-amplitude unidirectional rotary motion fueled by UV light and heat. ${ }^{75}$ In the present study, we show that such rotary motion can be driven by visible light through linker-to-linker energy transfer. The framework was constructed from two functional linkers: a porphyrin used as both linker dictating the connectivity of the framework and light-harvesting unit and a bispyridyl-derived molecular motor serving as a pillar and able to undergo rotary motion (Figure 1). In the resulting supramolecular architecture the backbone of the framework is not only a passive "scaffolding" but also plays an active role by absorbing visible light and transferring the collected energy to the molecular motor struts, thus driving its rotary motion. This dual-function

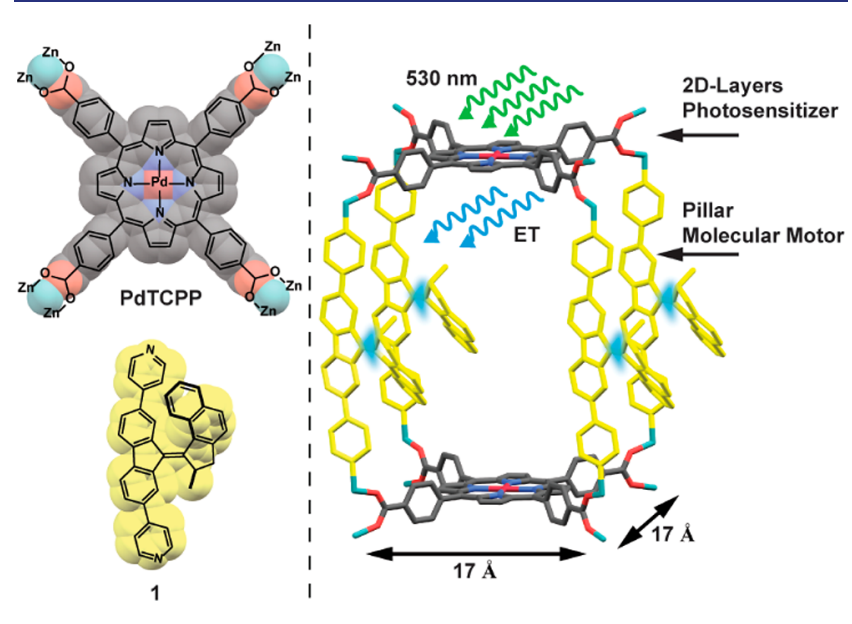

Figure 1. Structures of PdTCPP (left, top) and bispyridyl molecular motor 1 (left, bottom) used as linkers for construction of the MOF framework, and schematic representation of the rotation of molecular motor $\mathbf{1}$ incorporated as struts in the motorized pillared-paddlewheel PdTCPP MOF driven by energy transfer from a PdTCPP sensitizer (right). Relevant approximate dimensions of the unit cell are given.
MOF was obtained using a postsynthetic functionalization method from a parent $\mathrm{Zn}$ pillared-paddlewheel MOF bearing a palladium-porphyrin tetracarboxylic acid linker (PdTCPP) (Figure 1, top left) and bispyridyl pillars (Figure 1, bottom left). The chosen MOF scaffold provides the proximity of both linkers, allowing for efficient energy transfer between the chromophores and the large free volume that is essential for unhindered rotation of the light-driven molecular motor in the solid state (Figure 1). A key challenge, presented by this approach, is in demonstrating the functioning of the material by spectroscopic methods due to the overwhelming spectroscopic properties of the porphyrin chromophore. This unit, which is central to the visible-light-driven functionality, also precludes standard spectroscopic analysis of the motor function; however, near-infrared Raman spectroscopy (1064 $\mathrm{nm}$ ) enables full characterization of the motor function.

\section{RESULTS AND DISCUSSION}

Design, Synthesis, and Characterization of a Motorized Metal-Organic Framework. For the desired MOF a zinc pillared-paddlewheel scaffold was used, related to the framework we reported recently. ${ }^{75}$ In the chosen structure, the nodes of the framework, which is the zinc paddlewheel clusters, are connected by porphyrin tetracarboxylic acid linkers (PdTCPP) forming two-dimensional layers, which are pillared by the bispyridine-derived linker $\mathbf{1}$ (Figure 1). We designed the system in such a way that the size of the PdTCPP linker will ensure sufficient lateral separation of the pillars bearing a molecular motor function, generating free volume critical for uncompromised rotation of the molecular motor (in the designed structure, the distance between the nodes in the [100] and [010] planes is approximately $17 \AA$, Figure 1). Furthermore, the length of bispyridyl-derived molecular motor pillar $1\left(\mathrm{~N}-\mathrm{N}\right.$ distance $\left.15.6 \AA^{75}\right)$ should separate the porphyrin layers sufficiently to prevent competing interlayer porphyrin-porphyrin exciton transport. Finally, the nodes of the framework were based on closed-shell $\mathrm{d}^{10}$ configuration $\mathrm{Zn}^{2+}$ cations in order to exclude any undesired energy transfer between PdTCPP and nodes. Since MOFs of this topology are typically synthesized under relatively harsh conditions with the presence of strong mineral acids, ${ }^{76}$ it was decided to prepare the final material using a postsynthetic method, i.e., solventassisted linker exchange (SALE) developed by Farha and Hupp. ${ }^{77-81}$ In this process, bispyridine-derived pillars of the pillared MOFs can be exchanged for different bispyridyl linkers of similar length under neutral conditions, which prevents side reactions and decomposition of the acid-sensitive linkers. ${ }^{77}$ Furthermore, it was demonstrated that with this method shorter pillars can also be exchanged for longer pillars, thereby making this approach suitable for fabrication of MOFs with larger unit cell parameters. ${ }^{79}$ Initial attempts to grow the desired parent structure with $N, N^{\prime}$-di(4-pyridyl)-1,4,5,8naphthalenetetracarboxydiimide ${ }^{75}$ were largely unsuccessful and gave mixtures of products consisting predominately of interpenetrated frameworks analogous to the previously described interpenetrated porphyrinic frameworks. ${ }^{82,83}$ To overcome this tendency of formation of the interpenetrated structure a shorter linker, meso- $\alpha, \beta$-di(4-pyridyl) glycol (DPG, see Figure $2 \mathrm{a}$ for structure), was employed. A novel pillaredpaddlewheel framework was synthesized in a solvothermal reaction between PdTCPP, DPG, $\mathrm{Zn}\left(\mathrm{NO}_{3}\right)_{2} \cdot 6 \mathrm{H}_{2} \mathrm{O}$, and tetrafluoroboric acid in a binary solvent mixture (DMF/ $\mathrm{EtOH}$ ) providing square-shaped crystals (Figure 2b, top). It is 

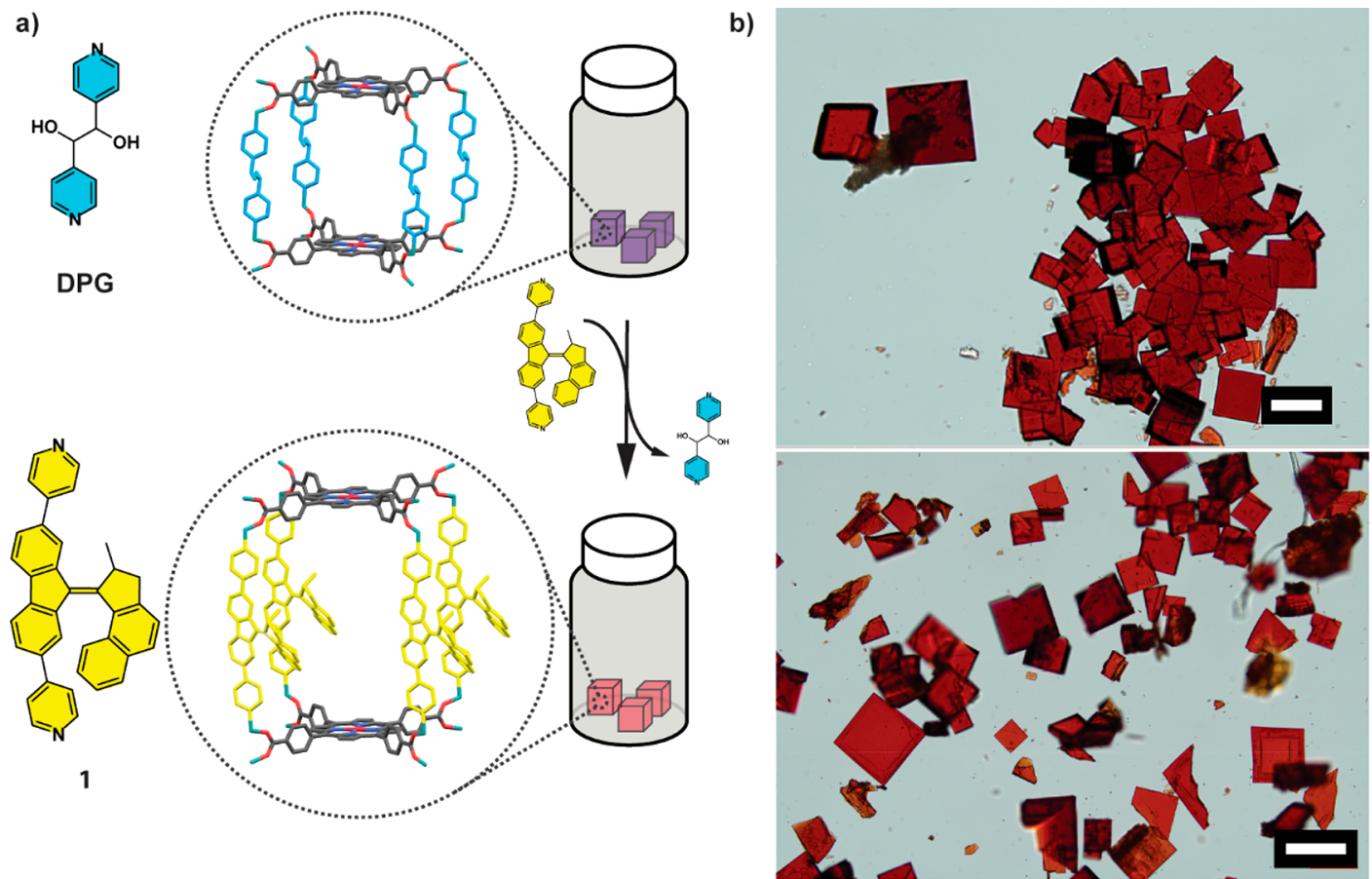

c)

d)
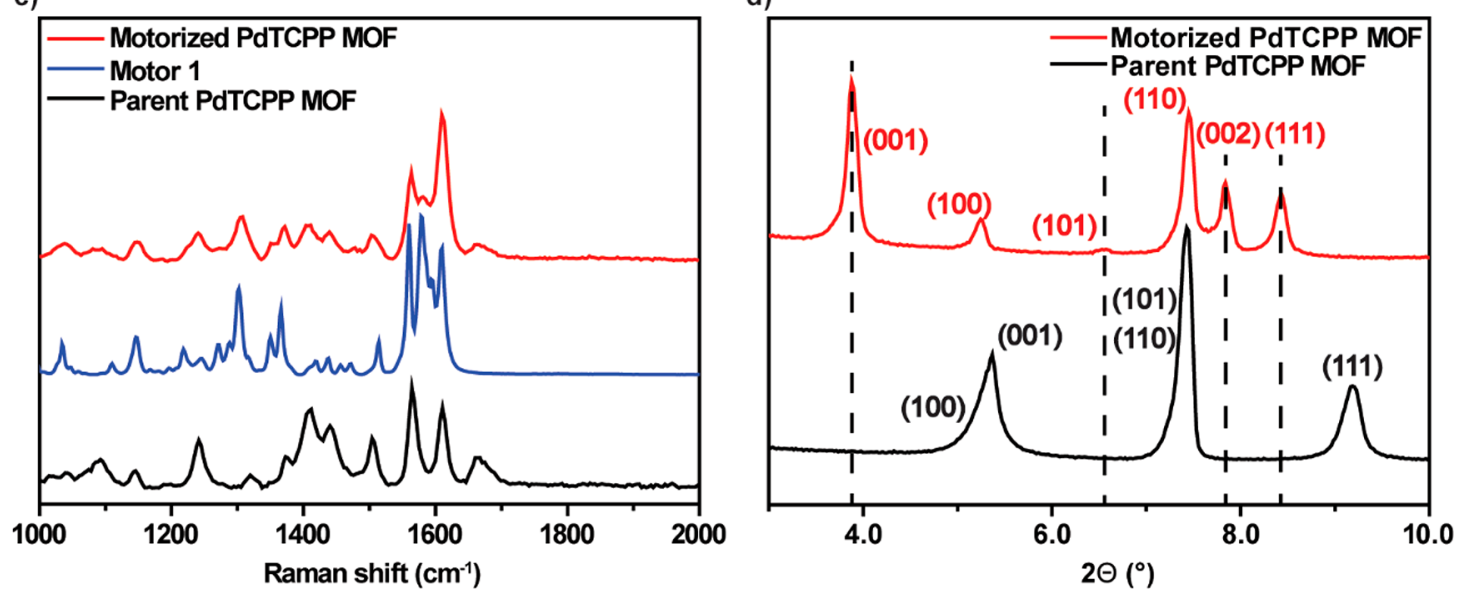

Figure 2. (a) Synthesis of the motorized pillared-paddlewheel MOF via SALE from parent MOF bearing DPG pillars by exchange with molecular motor 1. (b) Optical micrograph of the parent PdTCPP DPG-based MOF (top) and motorized PdTCPP 1-based MOF (bottom) crystals obtained via linker exchange (SALE) (scale bar $100 \mu \mathrm{m}$ ). (c) Raman spectra of the parent pillared-paddlewheel MOF (black spectrum, $1064 \mathrm{~nm}$, $250 \mathrm{~mW}$ ), bispyridyl molecular motor (blue spectrum, $785 \mathrm{~nm}, 50 \mathrm{~mW}$ ), and motorized pillared-paddlewheel MOF (red spectrum, $1064 \mathrm{~nm}, 250$ $\mathrm{mW}$ ). (d) Comparison of the experimental PXRD patterns of parent MOF (black, bottom pattern) and motorized MOF (red, top pattern). Miller indices of planes corresponding to the peaks are given in brackets. Vertical dashed lines indicate peaks in the PXRD pattern of motorized MOF, corresponding to $(h k l)$ (where $l \neq 0$ ) planes.

of note that when the reaction was carried out under less acidic conditions predominantly needle-like crystals (Figure S7a) of a 3-fold interpenetrated framework with zigzag structure were obtained (Figure S7b). Characterization by ${ }^{1} \mathrm{H}$ NMR $\left(d_{6}\right.$ DMSO) spectroscopy of the digested (using $\mathrm{D}_{2} \mathrm{SO}_{4}$ ) squareshaped crystals of the pillared-paddlewheel MOF showed the expected 1:1 ratio of DPG and PdTCPP linkers (Figures S1 and S2). The initial refinement of the single-crystal (SC) X-ray diffraction data collected from the target MOF revealed the expected layered structure composed of PdTCPP and Zn cations, while the DPG pillars could not be resolved, presumably due to rotational disorder (Figure S5). Nevertheless, the interlayer distance of $9.2 \AA$ ( $\mathrm{N}-\mathrm{N}$ distance between pyridyl nitrogens coordinated to paddlewheel clusters) determined from the structure corresponded well with the N-N distance (9.4 $\AA$, see SI section 13 ) in the DPG linker, indicating that DPG pillars are intercalating the layers of the framework (Figure S5). The powder X-ray diffraction data (PXRD), acquired under solvent-saturated conditions, corroborated bulk crystallinity and phase purity of the sample (Figures 2d and S8). Furthermore, Pawley refinement showed negligible differences between the experimental and the simulated diffraction patterns, further indicating formation of the target pillared structure (Figures S5 and S9, Table S2). Elemental analysis corroborated the anticipated elemental composition of the parent MOF (see SI, section 2). Subsequently, the parent DPG pillars were exchanged for bispyridyl molecular motor 1 by means of SALE (Figure 2a), which was carried out by soaking the crystals of parent MOF in a DMF solution of bispyridyl molecular motor 1 at $80{ }^{\circ} \mathrm{C}$ for 
a)

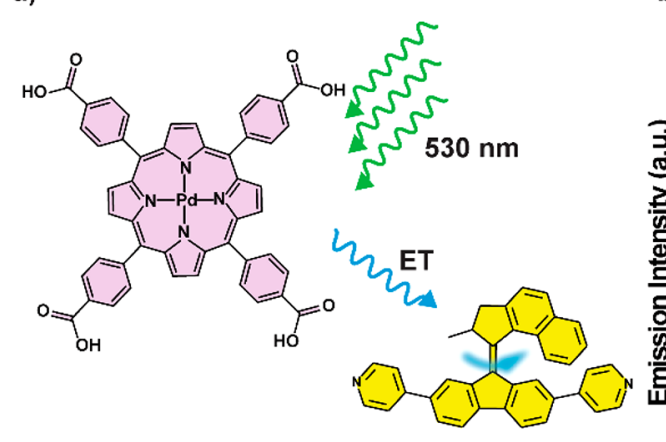

b)

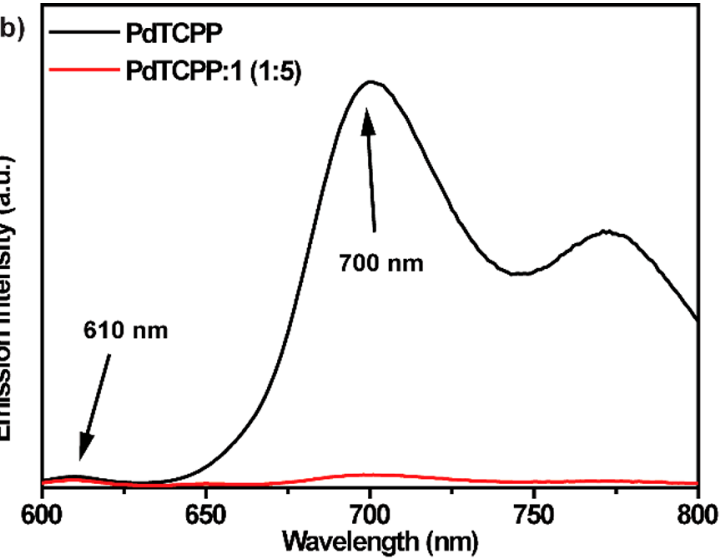

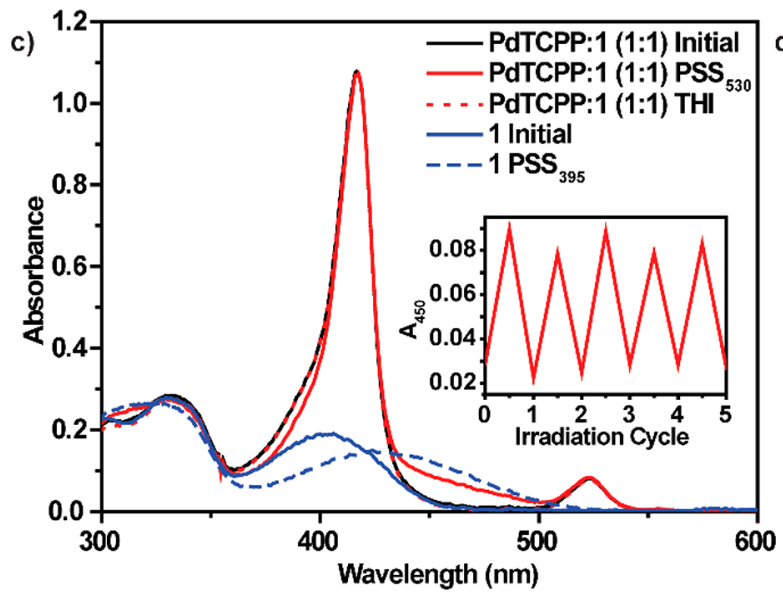

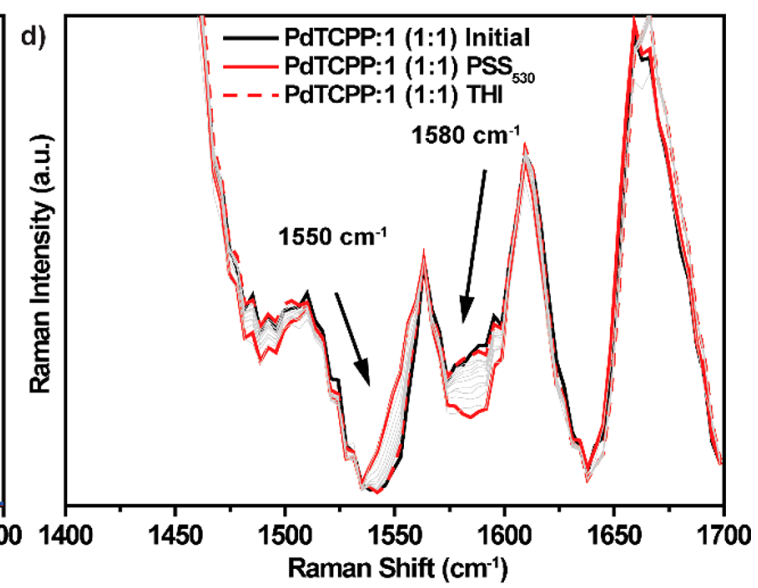

Figure 3. (a) Triplet-triplet sensitization of the light-driven rotary motion of molecular motor 1 by intermolecular energy transfer from PdTCPP. (b) Emission spectra $\left(\lambda_{\text {exc }}=530 \mathrm{~nm}\right.$ ) of PdTCPP (black spectrum, $44.6 \mu \mathrm{M}, \mathrm{DMF}$ ) and a mixture of PdTCPP and molecular motor 1 (red spectrum, 1:5 molar ratio of PdTCPP:1). Emission maxima of fluorescence $(610 \mathrm{~nm})$ and phosphorescence $(700 \mathrm{~nm})$ are indicated with arrows. (c) UV-vis absorption spectra $\left(-20^{\circ} \mathrm{C}, 6.1 \mu \mathrm{M}, \mathrm{DMF}\right)$ of 1 (blue solid line) irradiated at $395 \mathrm{~nm}$ to the photostationary state (blue dashed line), a mixture of PdTCPP and $\mathbf{1}$ (1:1 molar ratio, black solid line), a mixture of PdTCPP and $\mathbf{1}$ irradiated at 530 nm to the photostationary state (red solid line), and photostationary state mixture after thermal helix inversion (red dashed line). (Inset) Changes in absorbance followed at $450 \mathrm{~nm}$ upon multiple irradiation and heating cycles. (d) Changes in the Raman spectrum (1064 nm, $250 \mathrm{~mW}$ ) of a mixture of PdTCPP and 1 in DMF (black solid line), after irradiation at $530 \mathrm{~nm}$ at $-20^{\circ} \mathrm{C}$ to a photostationary state (red solid line), and after thermal helix inversion (red dashed line). Arrows indicate bands characteristic of the metastable isomer.

$48 \mathrm{~h}$ (the solution of 1 was replaced with a fresh solution after $24 \mathrm{~h}$ ) to achieve full exchange as indicated by ${ }^{1} \mathrm{H}$ NMR spectroscopy of digested crystals (Figures $2 \mathrm{~b}$, bottom, S1, and S3). Comparison of the Raman spectra of parent and motorized PdTCPP MOFs revealed the presence of additional bands characteristic of molecular motor 1 in the spectrum of motorized MOF, further supporting the successful exchange of the pillars (Figure 2c). As with the parent MOF, the SC X-ray structure of motorized MOF could only be partially resolved. From the refinement of the data the PdTCPP units and $\mathrm{Zn}$ paddlewheel clusters forming a layered structure could be confirmed, while the disorder between the layers precluded the interpretation of the electron density of the intercalating units (Figure S6). Nevertheless, the clear increase in the interlayer distance to $15.7 \AA$ (N-N distance between pyridyl nitrogens coordinated to paddlewheel clusters) corroborated the incorporation of longer pillars, consistent with the length of the molecular motor $\mathbf{1}(\mathrm{N}-\mathrm{N}$ distance in DFT-optimized structure $\mathrm{B} 3 \mathrm{LYP} / 6-31 \mathrm{G}(\mathrm{d}, \mathrm{p}) \quad 15.4 \AA) .{ }^{75}$ In addition, the expansion of the elementary unit cell in the [001] direction was confirmed by the changes observed in positions of the peaks in the PXRD diffractograms. In comparison to the PXRD of the parent MOF, significant shifts to a smaller diffraction angle were observed for the peaks ascribed to reflections from planes perpendicular and oblique to the [001] direction, while peaks corresponding to reflections from planes parallel to the [001] direction remained unchanged (Figures $2 \mathrm{~d}$ and S8). Furthermore, Pawley refinement showed good agreement between the dimensions of the targeted motorized PdTCPP MOF unit cell and the experimental PXRD pattern (Figures S8 and S9, Table S2). Finally, elemental analysis was consistent with the anticipated elemental composition of the parent MOF (see SI, section 2).

Energy Transfer, Photochemical, and Thermal Isomerization in Solution. Intermolecular energy transfer between the porphyrin (PdTCPP) and molecular motor $\mathbf{1}$ in solution was characterized by emission spectroscopy (Figure $3 \mathrm{~b})$. Deoxygenated solutions of PdTCPP excited at $530 \mathrm{~nm}$ show weak fluorescence at $610 \mathrm{~nm}$ and a strong emission band characteristic of phosphorescence at $700 \mathrm{~nm}$ (Figure 3b, black line) with a lifetime of ca. $221 \mu$ s (Figures S14-16, Table S3) ${ }^{84}$ For mixtures of PdTCPP and molecular motor 1 the intensity of the phosphorescence was substantially reduced with a decrease in phosphorescence lifetime to ca. $15 \mu \mathrm{s}$ (1:1 ratio of PdTCPP:1) and ca. $5 \mu$ s (1:5 ratio of PdTCPP:1, Figures S14-16, Table S3), in line with energy transfer 
between triplet states of the porphyrin and motor $\mathbf{1}$ (Figure $3 \mathrm{~b}$, red line). Stern-Volmer plots (emission intensity and lifetime, Figures S14 and S16, respectively) with concentrations of 1 between 0.0 and $223.0 \mu \mathrm{M}$ were linear, confirming dynamic quenching of the phosphorescence of PdTCPP, thus excluding formation of aggregates in the concentration range studied. Linear fitting of the data gave an intermolecular quenching rate constant $k_{\mathrm{q}}=9.0 \pm 0.3 \times 10^{8} \mathrm{M}^{-1} \mathrm{~s}^{-1}$ approaching the Smoluchowski limit of the diffusion-limited rate constant in DMF $\left(7.6 \times 10^{9} \mathrm{M}^{-1} \mathrm{~s}^{-1}\right.$ at $\left.20{ }^{\circ} \mathrm{C}\right),{ }^{85}$ suggesting that the energy transfer between PdTCPP and $\mathbf{1}$ is likely under diffusion control (Figures S14 and S16). ${ }^{86}$

Intermolecular sensitization of the rotary motion of motor 1 in solution was studied with UV-vis absorption, ${ }^{1} \mathrm{H} \mathrm{NMR}$, and Raman spectroscopies (Figures 3c, 3d, and S4). In the UV-vis absorption spectra the region characteristic of the main absorption band of the molecular motor 1 (maximum $\approx 400$ $\mathrm{nm}$, Figure 3c, blue solid line) is dominated by the strong Soret band of PdTCPP (Figure 3c, black solid line). Nevertheless, irradiation of the argon-purged solution of 1 and PdTCPP (1:1 ratio of 1:PdTCPP) at $530 \mathrm{~nm}$ (Q-band of the porphyrin) led to a bathochromic shift of the absorption in the region of the Soret band (Figure $3 c$, red solid line), consistent with formation of the metastable isomer of the molecular motor (Figure 3c, blue dashed lines). Subsequent warming of the sample led to the recovery of the original spectrum, consistent with the recovery of the stable isomer by thermal helix inversion (Figure $3 b$, red dashed line). An isosbestic point was maintained at $323 \mathrm{~nm}$ throughout both photochemical and thermal processes, as expected for unimolecular reactions (Figure S12). Furthermore, the irradiation/thermal isomerization cycles could be performed for at least five consecutive cycles without noticeable fatigue or degradation (Figure 3c, inset). The rate of the thermal helix inversion of bispyridyl motor 1 in the presence of PdTCPP in DMF was determined by following the exponential decrease of the absorbance at $440 \mathrm{~nm}$ over a range of temperatures (6-14 ${ }^{\circ} \mathrm{C}$, Figure S13). Eyring plot analysis showed that the Gibbs free energy of activation of the thermal helix inversion of the metastable isomer of 1 in this mixture $\left(\Delta^{\ddagger} G\left(20^{\circ} \mathrm{C}\right)=88.0 \pm\right.$ $0.4 \mathrm{~kJ} \mathrm{~mol}^{-1}, t_{1 / 2}=9.1 \mathrm{~min}$, Figure S13) is essentially the same as the previously determined value in $\operatorname{DMF}^{75}\left(\Delta^{\ddagger} G\left(20{ }^{\circ} \mathrm{C}\right)=\right.$ $\left.87.7 \pm 0.6 \mathrm{~kJ} \mathrm{~mol}^{-1}, t_{1 / 2}=8.0 \mathrm{~min}\right)$, thereby demonstrating that bispyridyl motor 1 can operate similarly via direct excitation and triplet sensitization. In the Raman spectra of the equimolar mixture of PdTCPP and 1 in DMF, bands characteristic of PdTCPP partially overlap and obscure bands characteristic of 1 (Figure 3d, black spectrum). Nonetheless, the features consistent with sequential photochemical and thermal isomerization of $\mathbf{1}$ could be readily observed with Raman spectroscopy. Irradiation of this mixture at $530 \mathrm{~nm}$ at low temperature $\left(-20{ }^{\circ} \mathrm{C}\right.$, sufficient to prevent thermal helix inversion over the time scale of the experiment) led to a decrease in the Raman scattering at $1580 \mathrm{~cm}^{-1}$ with a concomitant increase at $1550 \mathrm{~cm}^{-1}$. Warming to room temperature led to gradual recovery of the initial spectrum (Figure 3d). The intermolecular energy transfer-induced photoisomerization of motor $\mathbf{1}$ was monitored with lowtemperature ${ }^{1} \mathrm{H}$ NMR spectroscopy (Figure S4). After irradiation of an equimolar mixture of 1 and PdTCPP at $530 \mathrm{~nm}$ and $-30{ }^{\circ} \mathrm{C}$, a new set of upfield-shifted ${ }^{1} \mathrm{H}$ NMR resonances was observed in the aliphatic part of the spectrum, characteristic of the metastable isomer. Warming the sample resulted in full recovery of the original spectrum and hence of the stable isomer. The photostationary state ratio of metastable and stable isomers of $\mathbf{1}$, established upon irradiation at $530 \mathrm{~nm}$, was approximately 1:1 (Figure S4), consistent with changes observed by Raman spectroscopy (Figure 3d), which showed a $\sim 50 \%$ decrease in the intensity of the bands characteristic of the stable isomer $\left(1580 \mathrm{~cm}^{-1}\right)$.

Energy Transfer, Photochemical, and Thermal Isomerization in the Solid State. Since pillared $\mathrm{Zn}$ paddlewheel MOFs are known to lose crystallinity or undergo structural collapse upon solvent removal, all of the experiments involving PdTCPP MOFs were conducted in solvent (DMF)saturated conditions. ${ }^{79}$ The extent of the energy transfer between 1 and PdTCPP linkers in motorized MOF was determined with steady-state and time-resolved emission spectroscopy.

Upon excitation at $530 \mathrm{~nm}$ the parent PdTCPP MOF showed a similar emission spectrum to that of PdTCPP in DMF with a small hypsochromic shift of both fluorescence and phosphorescence (Figure 4a). Conversely, in the emission spectrum of the motorized PdTCPP MOF a strong decrease in the phosphorescence intensity was observed, consistent with the energy transfer between the linkers (Figure 4a).
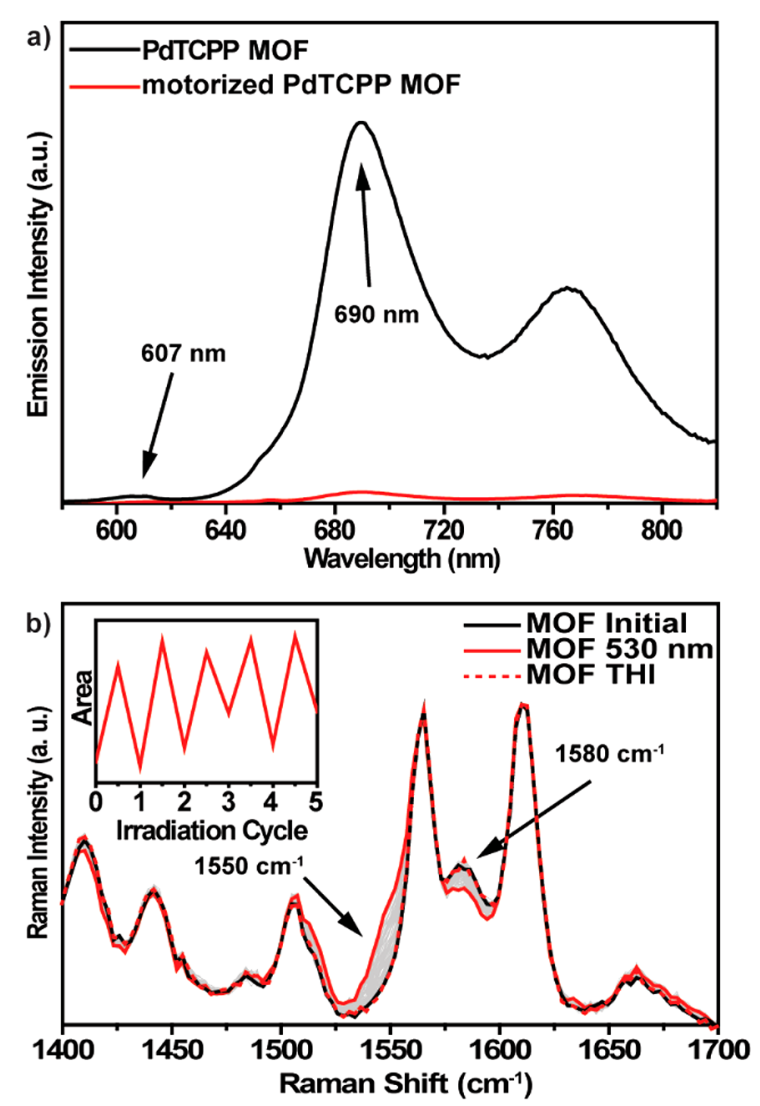

Figure 4. (a) Comparison of the emission spectra $\left(\lambda_{\mathrm{exc}}=530 \mathrm{~nm}\right)$ of DMF suspensions of parent PdTCPP MOF (black line) and motorized PdTCPP MOF (red line). (b) Changes in the Raman spectrum (1064 nm, $250 \mathrm{~mW}, 40 \mathrm{~s}$ integration time) of the motorized PdTCPP MOF sample (black solid line) upon irradiation at $530 \mathrm{~nm}$ (red solid line) and subsequent thermal isomerization (red dashed line). (Inset) Changes in the area around $1550 \mathrm{~cm}^{-1}$ followed upon multiple photochemical/thermal isomerization cycles. Label of ordinate, "Area", refers to the integrated area between 1530 and $1551 \mathrm{~cm}^{-1}$. 
Furthermore, a significant drop in the porphyrin phosphorescence lifetime was observed from ca. $100 \mu \mathrm{s}$ for the parent MOF to ca. $10 \mu \mathrm{s}$ for the motorized MOF (Figures S17 and S18). The difference between the phosphorescence lifetimes of PdTCPP in solution and in the parent MOF originates from the effect of excessive scattering from the latter; nevertheless, the large decrease in emission lifetime between parent and motorized MOF clearly indicates energy transfer between 1 and PdTCPP linkers in MOF.

The rotary motion of motor 1 inserted in the MOF scaffold was followed with NIR-Raman spectroscopy (see SI section 12 for other spectra). Previously, we demonstrated that this technique is particularly convenient to study the photochemical and thermal isomerization of rotary molecular motors in condensed phase as it allows for unambiguous correlation of spectral data with the structural changes that these molecules exhibit in response to light and heat stimuli. ${ }^{75}$ Upon exposure of the polycrystalline motorized PdTCPP MOF sample to green light $(530 \mathrm{~nm})$ a gradual decrease in the Raman intensity at $1580 \mathrm{~cm}^{-1}$ with concomitant increase in scattering intensity at $1550 \mathrm{~cm}^{-1}$ was observed (Figure $4 \mathrm{~b}$ ). Similar spectral features were detected upon photochemical isomerization of molecular motor $\mathbf{1}$ in solution and therefore could be ascribed to the same photochemical process. Furthermore, Raman spectroscopy showed that for thin samples the photostationary state of 1 reached via triplet sensitization in motorized PdTCPP MOF was similar to that in solution (Figure S22). Taking into consideration the molar absorptivity of PdTCPP at $532 \mathrm{~nm}$ and the concentration of molecular motor 1 in the crystal of the motorized MOF, the penetration depth for the excitation light in these crystals is likely no more than a few micrometers, and therefore, we envision the future application of these materials to be based on the surface-mounted MOFs (SURMOFs) or single-crystal devices. ${ }^{87}$ When the irradiation was discontinued, the initial Raman spectrum was recovered gradually, indicating thermal relaxation of the metastable to stable isomer. The barrier of the thermal relaxation at room temperature was determined by monitoring the changes in the bands area characteristic of the metastable isomer (Figures S23-25 and Table S3). The Gibbs free energy of activation for this process $\left(\Delta^{\ddagger} G\left(20^{\circ} \mathrm{C}\right)\right)$ was $88.7 \pm 0.8 \mathrm{~kJ} \mathrm{~mol}^{-1}\left(t_{1 / 2} \approx 13\right.$ $\mathrm{min})$ and corresponded well to the barrier determined in DMF solution $\left(88.0 \pm 0.4 \mathrm{~kJ} \mathrm{~mol}^{-1}, t_{1 / 2} \approx 9 \mathrm{~min}\right)$. The good agreement between the barriers in solution and the solid material shows that molecular motor 1 can perform its large amplitude rotary motion uncompromised while incorporated in PdTCPP MOF. Furthermore, irradiation/thermal relaxation steps could be repeated over five cycles (Figure $4 \mathrm{~b}$, inset) without any noticeable sign of fatigue or photodegradation, indicating high stability of the framework.

\section{CONCLUSIONS}

In conclusion, we established that the photoisomerization of the molecular motor pillars in a porphyrin $\mathrm{Zn}$ paddlewheel MOF can be driven with visible light by triplet sensitization. The desired motorized MOF was constructed by postsynthetic linker exchange (SALE) from the newly developed parent PdTCPP MOF bearing DPG pillars. Exchange of these pillars with the longer bispyridyl motor 1 resulted in the expected expansion of the elementary cell in the $c$ direction as shown by the SC X-ray and PXRD data. Due to the spatial coarrangement of the chromophores in the motorized MOF, the energy transfer between photosensitizer (2D layers) and molecular motor (pillars) was found to be efficient, and the photochemical isomerization of the molecular motor could be achieved with green $530 \mathrm{~nm}$ light. Additionally, it was shown that the rate of the thermal helix inversion step of the molecular motors incorporated in the material scaffold is essentially the same as that observed in solution, owing to the large free volume present in the framework. The demonstration of visible-light-driven rotary motion of a molecular motor in a metal-organic framework opens many perspectives for future applications, such as membranes and pumps able to accelerate flow of gases or in combination with catalytic function and miniaturized chemical reactors able to accelerate inflow of reactants and outflow of products, powered by noninvasive visible light. ${ }^{88}$ Furthermore, we envision that this strategy may be used to expand the scope of photosensitizers and molecular motors to achieve an even further shift of the excitation wavelength toward red light.

\section{ASSOCIATED CONTENT}

\section{SI Supporting Information}

The Supporting Information is available free of charge at https://pubs.acs.org/doi/10.1021/jacs.0c03063.

Synthetic procedures and characterization, additional UV-vis and Raman spectra, Eyring plot, details on quantum yield, and lifetime determination (PDF)

X-ray crystal structure of parent PdTCPP-DPG MOF (CIF)

X-ray crystal structure of interpenetrated PdTCPP-DPG MOF (CIF)

X-ray crystal structure of motorized PdTCPP-1 MOF (CIF)

Modeled structure of motorized PdTCPP-1 MOF (CIF)

Modeled structure of parent PdTCPP-DPG MOF (CIF)

\section{AUTHOR INFORMATION}

\section{Corresponding Authors}

Wesley R. Browne - Centre for Systems Chemistry, Stratingh Institute for Chemistry and Molecular Inorganic Chemistry Group, Stratingh Institute for Chemistry, University of Groningen, 9747 AG Groningen, The Netherlands; ๑ orcid.org/0000-0001-5063-6961; Email: W.R.Browne@ rug.nl

Ben L. Feringa - Centre for Systems Chemistry, Stratingh Institute for Chemistry, University of Groningen, 9747 AG Groningen, The Netherlands; O orcid.org/0000-0003-05888435; Email: B.L.Feringa@rug.nl

\section{Authors}

Wojciech Danowski - Centre for Systems Chemistry, Stratingh Institute for Chemistry, University of Groningen, 9747 AG Groningen, The Netherlands; $\odot$ orcid.org/0000-0002-85888912

Fabio Castiglioni - Department of Materials Science, University of Milano Bicocca, 20125 Milan, Italy

Andy S. Sardjan - Molecular Inorganic Chemistry Group, Stratingh Institute for Chemistry, University of Groningen, 9747AG Groningen, The Netherlands

Simon Krause - Centre for Systems Chemistry, Stratingh Institute for Chemistry, University of Groningen, 9747 AG 
Groningen, The Netherlands; $\odot$ orcid.org/0000-0001-95048514

Lukas Pfeifer - Centre for Systems Chemistry, Stratingh Institute for Chemistry, University of Groningen, 9747 AG Groningen, The Netherlands

Diederik Roke - Centre for Systems Chemistry, Stratingh Institute for Chemistry, University of Groningen, 9747 AG Groningen, The Netherlands

Angiolina Comotti - Department of Materials Science, University of Milano Bicocca, 20125 Milan, Italy; 자이.org/ 0000-0002-8396-8951

Complete contact information is available at:

https://pubs.acs.org/10.1021/jacs.0c03063

\section{Funding}

This work was supported financially by The Netherlands Organization for Scientific Research (NWO CW), the European Research Council (ERC, advanced grant no. 694345 to B.L.F.), and the Ministry of Education, Culture and Science (Gravitation Program no. 024.001.035). A.C. acknowledges MIUR grant "Dipartimenti di Eccellenza-2017 "Materials For Energy" and PRIN grant no. 20173L7W8K. S.K. acknowledges support of the Alexander von Humboldt foundation. We thank the University of Groningen for access to the Peregrine Computing Cluster.

\section{Notes}

The authors declare no competing financial interest.

\section{ACKNOWLEDGMENTS}

Jacob Bass is acknowledged for help with acquiring PXRD data. We greatly acknowledge Sander J. Wezenberg for discussions and helpful suggestions.

\section{REFERENCES}

(1) Dietrich-Buchecker, C.; Jimenez-Molero, M. C.; Sartor, V.; Sauvage, J.-P. Rotaxanes and catenanes as prototypes of molecular machines and motors. Pure Appl. Chem. 2003, 75, 1383-1393.

(2) Bruns, C. J.; Stoddart, J. F. The Nature of the Mechanical Bond: From Molecules to Machines; Wiley: Hoboken, NJ, 2016.

(3) Balzani, V.; Venturi, M.; Credi, A. Molecular devices and machines: a journey into the nano world; Wiley-VCH: Weinheim, 2003.

(4) Schliwa, M. Molecular motors; Wiley-VCH: Weinheim, 2003.

(5) Kinbara, K.; Aida, T. Toward Intelligent Molecular Machines: Directed Motions of Biological and Artificial Molecules and Assemblies. Chem. Rev. 2005, 105, 1377-1400.

(6) Erbas-Cakmak, S.; Leigh, D. A.; McTernan, C. T.; Nussbaumer, A. L. Artificial Molecular Machines. Chem. Rev. 2015, 115, 1008110206.

(7) García-López, V.; Liu, D.; Tour, J. M. Light-Activated Organic Molecular Motors and Their Applications. Chem. Rev. 2020, 120, 79124.

(8) Browne, W. R.; Feringa, B. L. Making molecular machines work. Nat. Nanotechnol. 2006, 1, 25-35.

(9) Koumura, N.; Zijlstra, R. W. J.; van Delden, R. A.; Harada, N.; Feringa, B. L. Light-driven monodirectional molecular rotor. Nature 1999, 401, 152-155.

(10) Koumura, N.; Geertsema, E. M.; Meetsma, A.; Feringa, B. L. Light-driven molecular rotor: Unidirectional rotation controlled by a single stereogenic center. J. Am. Chem. Soc. 2000, 122, 12005-12006.

(11) van Leeuwen, T.; Lubbe, A. S.; Stacko, P.; Wezenberg, S. J.; Feringa, B. L. Dynamic control of function by light-driven molecular motors. Nat. Rev. Chem. 2017, 1, 96.

(12) Wang, J.; Feringa, B. L. Dynamic control of chiral space in a catalytic asymmetric reaction using a molecular motor. Science 2011, $331,1429-1432$.
(13) Astumian, R. D. Design principles for Brownian molecular machines: how to swim in molasses and walk in a hurricane. Phys. Chem. Chem. Phys. 2007, 9, 5067-5083.

(14) Coskun, A.; Banaszak, M.; Astumian, R. D.; Stoddart, J. F.; Grzybowski, B. A. Great expectations: can artificial molecular machines deliver on their promise? Chem. Soc. Rev. 2012, 41, 19-30.

(15) Carroll, G. T.; London, G.; Landaluce, T. F.; Rudolf, P.; Feringa, B. L. Adhesion of Photon-Driven Molecular Motors to Surfaces via 1,3-Dipolar Cycloadditions: Effect of Interfacial Interactions on Molecular Motion. ACS Nano 2011, 5, 622-630.

(16) van Delden, R. A.; ter Wiel, M. K. J.; Pollard, M. M.; Vicario, J.; Koumura, N.; Feringa, B. L. Unidirectional molecular motor on a gold surface. Nature 2005, 437, 1337-1340.

(17) Kaleta, J.; Chen, J.; Bastien, G.; Dračínský, M.; Mašát, M.; Rogers, C. T.; Feringa, B. L.; Michl, J. Surface Inclusion of Unidirectional Molecular Motors in Hexagonal Tris(o-phenylene)cyclotriphosphazene. J. Am. Chem. Soc. 2017, 139, 10486-10498.

(18) Wezenberg, S. J.; Croisetu, C. M.; Stuart, M. C. A.; Feringa, B. L. Reversible gel-sol photoswitching with an overcrowded alkenebased bis-urea supergelator. Chem. Sci. 2016, 7, 4341-4346.

(19) Chen, J.; Leung, F. K. C.; Stuart, M. C. A.; Kajitani, T.; Fukushima, T.; van der Giessen, E.; Feringa, B. L. Artificial musclelike function from hierarchical supramolecular assembly of photoresponsive molecular motors. Nat. Chem. 2018, 10, 132-138.

(20) Leung, F. K.-C.; van den Enk, T.; Kajitani, T.; Chen, J.; Stuart, M. C. A.; Kuipers, J.; Fukushima, T.; Feringa, B. L. Supramolecular Packing and Macroscopic Alignment Controls Actuation Speed in Macroscopic Strings of Molecular Motor Amphiphiles. J. Am. Chem. Soc. 2018, 140, 17724-17733.

(21) Li, Q.; Fuks, G.; Moulin, E.; Maaloum, M.; Rawiso, M.; Kulic, I.; Foy, J. T.; Giuseppone, N. Macroscopic contraction of a gel induced by the integrated motion of light-driven molecular motors. Nat. Nanotechnol. 2015, 10, 161-165.

(22) Foy, J. T.; Li, Q.; Goujon, A.; Colard-Itté, J. R.; Fuks, G.; Moulin, E.; Schiffmann, O.; Dattler, D.; Funeriu, D. P.; Giuseppone, N. Dual-light control of nanomachines that integrate motor and modulator subunits. Nat. Nanotechnol. 2017, 12, 540-545.

(23) Eelkema, R.; Pollard, M. M.; Vicario, J.; Katsonis, N.; Ramon, B. S.; Bastiaansen, C. W. M.; Broer, D. J.; Feringa, B. L. Nanomotor rotates microscale objects. Nature 2006, 440, 163.

(24) Pijper, D.; Jongejan, M. G. M.; Meetsma, A.; Feringa, B. L. Light-Controlled Supramolecular Helicity of a Liquid Crystalline Phase Using a Helical Polymer Functionalized with a Single Chiroptical Molecular Switch. J. Am. Chem. Soc. 2008, 130, 45414552.

(25) Orlova, T.; Lancia, F.; Loussert, C.; Iamsaard, S.; Katsonis, N.; Brasselet, E. Revolving supramolecular chiral structures powered by light in nanomotor-doped liquid crystals. Nat. Nanotechnol. 2018, 13, 304-308.

(26) Zou, C.; Sun, J.; Wang, M.; Wang, J.; Wu, Y.; Zhang, L.; Zhu, Z.; Xiong, G.; Jiang, L.; Ikeda, T.; Yang, H. A UV-Responsive Multifunctional Photoelectric Device Based on Discotic Columnar Nanostructures and Molecular Motors. Adv. Mater. 2019, 31, 1806016.

(27) van Leeuwen, T.; Heideman, G. H.; Zhao, D.; Wezenberg, S. J.; Feringa, B. L. In situ control of polymer helicity with a non-covalently bound photoresponsive molecular motor dopant. Chem. Commun. 2017, 53, 6393-6396.

(28) Pijper, D.; Feringa, B. L. Molecular transmission: Controlling the twist sense of a helical polymer with a single light-driven molecular motor. Angew. Chem., Int. Ed. 2007, 46, 3693-3696.

(29) Chen, K. Y.; Ivashenko, O.; Carroll, G. T.; Robertus, J.; Kistemaker, J. C. M.; London, G.; Browne, W. R.; Rudolf, P.; Feringa, B. L. Control of surface wettability using tripodal light-activated molecular motors. J. Am. Chem. Soc. 2014, 136, 3219-3224.

(30) Russew, M.-M.; Hecht, S. Photoswitches: From Molecules to Materials. Adv. Mater. 2010, 22, 3348-3360. 
(31) Lubbe, A. S.; van Leeuwen, T.; Wezenberg, S. J.; Feringa, B. L. Designing dynamic functional molecular systems. Tetrahedron 2017, 73, 4837-4848.

(32) van Leeuwen, T.; Pol, J.; Roke, D.; Wezenberg, S. J.; Feringa, B. L. Visible-Light Excitation of a Molecular Motor with an Extended Aromatic Core. Org. Lett. 2017, 19, 1402-1405.

(33) van Delden, R. A.; Koumura, N.; Schoevaars, A.; Meetsma, A.; Feringa, B. L. A donor-acceptor substituted molecular motor: unidirectional rotation driven by visible light. Org. Biomol. Chem. 2003, 1, 33-35.

(34) Pfeifer, L.; Scherübl, M.; Fellert, M.; Danowski, W.; Cheng, J.; Pol, J.; Feringa, B. L. Photoefficient 2nd generation molecular motors responsive to visible light. Chem. Sci. 2019, 10, 8768-8773.

(35) Wezenberg, S. J.; Chen, K.-Y.; Feringa, B. L. Visible-LightDriven Photoisomerization and Increased Rotation Speed of a Molecular Motor Acting as a Ligand in a Ruthenium(II) Complex. Angew. Chem., Int. Ed. 2015, 54, 11457-11461.

(36) Roke, D.; Wezenberg, S. J.; Feringa, B. L. Molecular rotary motors: Unidirectional motion around double bonds. Proc. Natl. Acad. Sci. U. S. A. 2018, 115, 9423-9431.

(37) Cnossen, A.; Hou, L.; Pollard, M. M.; Wesenhagen, P. V.; Browne, W. R.; Feringa, B. L. Driving Unidirectional Molecular Rotary Motors with Visible Light by Intra- And Intermolecular Energy Transfer from Palladium Porphyrin. J. Am. Chem. Soc. 2012, 134, 17613-17619.

(38) Perego, J.; Pedrini, J.; Bezuidenhout, C. X.; Sozzani, P. E.; Meinardi, F.; Bracco, S.; Comotti, A.; Monguzzi, A. Engineering Porous Emitting Framework Nanoparticles with Integrated Sensitizers for Low-Power Photon Upconversion by Triplet Fusion. Adv. Mater. 2019, 31, 1903309.

(39) Sakamoto, R.; Kume, S.; Sugimoto, M.; Nishihara, H. trans - cis Photoisomerization of Azobenzene-Conjugated Dithiolato-Bipyridine Platinum(II) Complexes: Extension of Photoresponse to Longer Wavelengths and Photocontrollable Tristability. Chem. - Eur. J. 2009, $15,1429-1439$.

(40) Venkataramani, S.; Jana, U.; Dommaschk, M.; Sonnichsen, F. D.; Tuczek, F.; Herges, R. Magnetic Bistability of Molecules in Homogeneous Solution at Room Temperature. Science 2011, 331, 445-448.

(41) Mercer-Smith, J. A.; Whitten, D. G. Photosensitization of stilbene isomerization by palladium and platinum porphyrins, an intermolecular quantum chain process. J. Am. Chem. Soc. 1978, 100, $2620-2625$.

(42) Serreli, V.; Lee, C. F.; Kay, E. R.; Leigh, D. A. A molecular information ratchet. Nature 2007, 445, 523-527.

(43) Jukes, R. T. F.; Adamo, V.; Hartl, F.; Belser, P.; De Cola, L. Photochromic Dithienylethene Derivatives Containing $\mathrm{Ru}(\mathrm{II})$ or Os(II) Metal Units. Sensitized Photocyclization from a Triplet State. Inorg. Chem. 2004, 43, 2779-2792.

(44) Yam, V. W.-W.; Ko, C.-C.; Zhu, N. Photochromic and Luminescence Switching Properties of a Versatile DiaryletheneContaining 1,10-Phenanthroline Ligand and Its Rhenium(I) Complex. J. Am. Chem. Soc. 2004, 126, 12734-12735.

(45) Howarth, A. J.; Liu, Y.; Li, P.; Li, Z.; Wang, T. C.; Hupp, J. T.; Farha, O. K. Chemical, thermal and mechanical stabilities of metalorganic frameworks. Nat. Rev. Mater. 2016, 1, 1-15.

(46) Li, H.; Eddaoudi, M.; O’Keeffe, M.; Yaghi, O. M. Design and synthesis of an exceptionally stable and highly porous metal-organic framework. Nature 1999, 402, 276-279.

(47) Furukawa, H.; Cordova, K. E.; O’Keeffe, M.; Yaghi, O. M. The chemistry and applications of metal-organic frameworks. Science 2013, 341, 1230444.

(48) Jones, C. L.; Tansell, A. J.; Easun, T. L. The lighter side of MOFs: structurally photoresponsive metal-organic frameworks. J. Mater. Chem. A 2016, 4, 6714-6723.

(49) Castellanos, S.; Kapteijn, F.; Gascon, J. Photoswitchable metal organic frameworks: Turn on the lights and close the windows. CrystEngComm 2016, 18, 4006-4012.
(50) McGonigal, P. R.; Deria, P.; Hod, I.; Moghadam, P. Z.; Avestro, A.-J.; Horwitz, N. E.; Gibbs-Hall, I. C.; Blackburn, A. K.; Chen, D.; Botros, Y. Y.; Wasielewski, M. R.; Snurr, R. Q.; Hupp, J. T.; Farha, O. K.; Stoddart, J. F. Electrochemically addressable trisradical rotaxanes organized within a metal-organic framework. Proc. Natl. Acad. Sci. U. S. A. 2015, 112, 11161-11168.

(51) Chen, Q.; Sun, J.; Li, P.; Hod, I.; Moghadam, P. Z.; Kean, Z. S.; Snurr, R. Q.; Hupp, J. T.; Farha, O. K.; Stoddart, J. F. A Redox-Active Bistable Molecular Switch Mounted inside a Metal-Organic Framework. J. Am. Chem. Soc. 2016, 138, 14242-14245.

(52) Williams, D. E.; Martin, C. R.; Dolgopolova, E. A.; Swifton, A.; Godfrey, D. C.; Ejegbavwo, O. A.; Pellechia, P. J.; Smith, M. D.; Shustova, N. B. Flipping the Switch: Fast Photoisomerization in a Confined Environment. J. Am. Chem. Soc. 2018, 140, 7611-7622.

(53) Dolgopolova, E. A.; Galitskiy, V. A.; Martin, C. R.; Gregory, H. N.; Yarbrough, B. J.; Rice, A. M.; Berseneva, A. A.; Ejegbavwo, O. A.; Stephenson, K. S.; Kittikhunnatham, P.; Karakalos, S. G.; Smith, M. D.; Greytak, A. B.; Garashchuk, S.; Shustova, N. B. Connecting Wires: Photoinduced Electronic Structure Modulation in Metal-Organic Frameworks. J. Am. Chem. Soc. 2019, 141, 5350-5358.

(54) Brown, J. W.; Henderson, B. L.; Kiesz, M. D.; Whalley, A. C.; Morris, W.; Grunder, S.; Deng, H.; Furukawa, H.; Zink, J. I.; Stoddart, J. F.; Yaghi, O. M. Photophysical pore control in an azobenzenecontaining metal-organic framework. Chem. Sci. 2013, 4, 2858.

(55) Furlong, B. J.; Katz, M. J. Bistable Dithienylethene-Based Metal-Organic Framework Illustrating Optically Induced Changes in Chemical Separations. J. Am. Chem. Soc. 2017, 139, 13280-13283.

(56) Zheng, Y.; Sato, H.; Wu, P.; Jeon, H. J.; Matsuda, R.; Kitagawa, $\mathrm{S}$. Flexible interlocked porous frameworks allow quantitative photoisomerization in a crystalline solid. Nat. Commun. 2017, 8, 1-6.

(57) Nikolayenko, V. I.; Herbert, S. A.; Barbour, L. J. Reversible structural switching of a metal-organic framework by photoirradiation. Chem. Commun. 2017, 53, 11142-11145.

(58) Gould, S. L.; Tranchemontagne, D.; Yaghi, O. M.; GarciaGaribay, M. A. The Amphidynamic Character of Crystalline MOF-5: Rotational Dynamics in a Free-Volume Environment. J. Am. Chem. Soc. 2008, 130, 3246-3247.

(59) Bracco, S.; Castiglioni, F.; Comotti, A.; Galli, S.; Negroni, M.; Maspero, A.; Sozzani, P. Ultrafast Molecular Rotors and Their $\mathrm{CO}_{2}$ Tuning in MOFs with Rod-Like Ligands. Chem. - Eur. J. 2017, 23, 11210-11215.

(60) Vogelsberg, C. S.; Uribe-Romo, F. J.; Lipton, A. S.; Yang, S.; Houk, K. N.; Brown, S.; Garcia-Garibay, M. A. Ultrafast rotation in an amphidynamic crystalline metal organic framework. Proc. Natl. Acad. Sci. U. S. A. 2017, 114, 13613-13618.

(61) Jiang, X.; Duan, H.-B.; Khan, S. I.; Garcia-Garibay, M. A. Diffusion-controlled rotation of triptycene in a metal-organic framework (MOF) sheds light on the viscosity of MOF-confined solvent. ACS Cent. Sci. 2016, 2, 608-613.

(62) Vukotic, V. N.; Harris, K. J.; Zhu, K.; Schurko, R. W.; Loeb, S. J. Metal-organic frameworks with dynamic interlocked components. Nat. Chem. 2012, 4, 456-460.

(63) Zhu, K.; Vukotic, V. N.; O’Keefe, C. A.; Schurko, R. W.; Loeb, S. J. Metal-organic frameworks with mechanically interlocked pillars: Controlling ring dynamics in the solid-state via a reversible phase change. J. Am. Chem. Soc. 2014, 136, 7403-7409.

(64) Vukotic, V. N.; O’Keefe, C. A.; Zhu, K.; Harris, K. J.; To, C.; Schurko, R. W.; Loeb, S. J. Mechanically Interlocked Linkers inside Metal - Organic Frameworks: Effect of Ring Size on Rotational Dynamics. J. Am. Chem. Soc. 2015, 137, 9643-9651.

(65) Zhu, K.; O’Keefe, C. A.; Vukotic, V. N.; Schurko, R. W.; Loeb, S. J. A molecular shuttle that operates inside a metal-organic framework. Nat. Chem. 2015, 7, 514-519.

(66) Deng, H.; Doonan, C. J.; Furukawa, H.; Ferreira, R. B.; Towne, J.; Knobler, C. B.; Wang, B.; Yaghi, O. M. Multiple Functional Groups of Varying Ratios in Metal-Organic Frameworks. Science 2010, 327, $846-850$ 
(67) Kong, X.; Deng, H.; Yan, F.; Kim, J.; Swisher, J. A.; Smit, B.; Yaghi, O. M.; Reimer, J. A. Mapping of Functional Groups in MetalOrganic Frameworks. Science 2013, 341, 882-885.

(68) Lee, C. Y.; Farha, O. K.; Hong, B. J.; Sarjeant, A. A.; Nguyen, S. T.; Hupp, J. T. Light-Harvesting Metal-Organic Frameworks (MOFs): Efficient Strut-to-Strut Energy Transfer in Bodipy and Porphyrin-Based MOFs. J. Am. Chem. Soc. 2011, 133, 15858-15861. (69) Kent, C. A.; Mehl, B. P.; Ma, L.; Papanikolas, J. M.; Meyer, T. J.; Lin, W. Energy Transfer Dynamics in Metal-Organic Frameworks. J. Am. Chem. Soc. 2010, 132, 12767-12769.

(70) Zhang, X.; Ballem, M. A.; Hu, Z.-J.; Bergman, P.; Uvdal, K. Nanoscale Light-Harvesting Metal-Organic Frameworks. Angew. Chem., Int. Ed. 2011, 50, 5729-5733.

(71) Son, H.-J.; Jin, S.; Patwardhan, S.; Wezenberg, S. J.; Jeong, N. C.; So, M.; Wilmer, C. E.; Sarjeant, A. A.; Schatz, G. C.; Snurr, R. Q.; Farha, O. K.; Wiederrecht, G. P.; Hupp, J. T. Light-Harvesting and Ultrafast Energy Migration in Porphyrin-Based Metal-Organic Frameworks. J. Am. Chem. Soc. 2013, 135, 862-869.

(72) So, M. C.; Wiederrecht, G. P.; Mondloch, J. E.; Hupp, J. T.; Farha, O. K. Metal-organic framework materials for light-harvesting and energy transfer. Chem. Commun. 2015, 51, 3501-3510.

(73) Williams, D. E.; Rietman, J. A.; Maier, J. M.; Tan, R.; Greytak, A. B.; Smith, M. D.; Krause, J. A.; Shustova, N. B. Energy Transfer on Demand: Photoswitch-Directed Behavior of Metal-Porphyrin Frameworks. J. Am. Chem. Soc. 2014, 136, 11886-11889.

(74) Park, J.; Feng, D.; Yuan, S.; Zhou, H.-C. Photochromic MetalOrganic Frameworks: Reversible Control of Singlet Oxygen Generation. Angew. Chem., Int. Ed. 2015, 54, 430-435.

(75) Danowski, W.; van Leeuwen, T.; Abdolahzadeh, S.; Roke, D.; Browne, W. R.; Wezenberg, S. J.; Feringa, B. L. Unidirectional rotary motion in a metal-organic framework. Nat. Nanotechnol. 2019, 14, 488-494.

(76) Farha, O. K.; Malliakas, C. D.; Kanatzidis, M. G.; Hupp, J. T. Control over Catenation in Metal- Organic Frameworks via Rational Design of the Organic Building Block. J. Am. Chem. Soc. 2010, 132, 950-952.

(77) Madrahimov, S. T.; Atesin, T. A.; Karagiaridi, O.; Sarjeant, A. A.; Farha, O. K.; Hupp, J. T.; Nguyen, S. T. Metal-organic frameworks containing (alkynyl)gold functionalities: A comparative evaluation of solvent-assisted linker exchange, de novo synthesis, and post-synthesis modification. Cryst. Growth Des. 2014, 14, 6320-6324.

(78) Karagiaridi, O.; Bury, W.; Mondloch, J. E.; Hupp, J. T.; Farha, $\mathrm{O}$. K. Solvent-assisted linker exchange: An alternative to the de novo synthesis of unattainable metal-organic frameworks. Angew. Chem., Int. Ed. 2014, 53, 4530-4540.

(79) Karagiaridi, O.; Bury, W.; Tylianakis, E.; Sarjeant, A. A.; Hupp, J. T.; Farha, O. K. Opening Metal-Organic Frameworks Vol. 2: Inserting Longer Pillars into Pillared-Paddlewheel Structures through Solvent-Assisted Linker Exchange. Chem. Mater. 2013, 25, 34993503.

(80) Bury, W.; Fairen-Jimenez, D.; Lalonde, M. B.; Snurr, R. Q.; Farha, O. K.; Hupp, J. T. Control over catenation in pillared paddlewheel metal-organic framework materials via solvent-assisted linker exchange. Chem. Mater. 2013, 25, 739-744.

(81) Burnett, B. J.; Barron, P. M.; Hu, C.; Choe, W. Stepwise Synthesis of Metal-Organic Frameworks: Replacement of Structural Organic Linkers. J. Am. Chem. Soc. 2011, 133, 9984-9987.

(82) Martinez-Bulit, P.; O’Keefe, C. A.; Zhu, K.; Schurko, R. W.; Loeb, S. J. Solvent and Steric Influences on Rotational Dynamics in Porphyrinic Metal-Organic Frameworks with Mechanically Interlocked Pillars. Cryst. Growth Des. 2019, 19, 5679-5685.

(83) Chung, H.; Barron, P. M.; Novotny, R. W.; Son, H. T.; Hu, C.; Choe, W. Structural variation in porphyrin pillared homologous series: Influence of distinct coordination centers for pillars on framework topology. Cryst. Growth Des. 2009, 9, 3327-3332.

(84) Vinogradov, S. A.; Wilson, D. F. Phosphorescence Lifetime Analysis with a Quadratic Programming Algorithm for Determining Quencher Distributions in Heterogeneous Systems. Biophys. J. 1994, 67, 2048-2059.
(85) Montalti, M.; Credi, A.; Prodi, L. P.; Gandolfi, M. T. Handbook of photochemistry, 3rd ed.; CRC/Taylor \& Francis: Boca Raton, 2006. (86) Lakowicz, J. R. Principles of fluorescence spectroscopy; Lakowicz, J. R., Ed., Springer: Boston, MA, 2006.

(87) Heinke, L.; Wöll, C. Surface-Mounted Metal-Organic Frameworks: Crystalline and Porous Molecular Assemblies for Fundamental Insights and Advanced Applications. Adv. Mater. 2019, 31, 1806324.

(88) Evans, J. D.; Krause, S.; Feringa, B. L. Cooperative and synchronized rotation in motorized porous frameworks: Impact on local and global transport properties of confined fluids. Faraday Discuss. 2020. DOI: 10.1039/D0FD00016G 